\title{
Effects of Plate Curvature on Thermo- Mechanical Performance of U-10Mo Monolithic Fuel Plates
}

Hakan Ozaltun, Hee Seok Roh, Walid Mohamed

November 2019

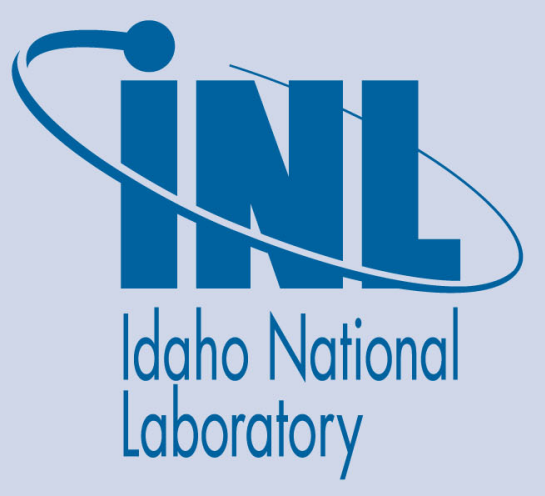

The INL is a U.S. Department of Energy National Laboratory operated by Battelle Energy Alliance 


\section{Effects of Plate Curvature on Thermo-Mechanical Performance of U-10Mo Monolithic Fuel Plates}

Hakan Ozaltun, Hee Seok Roh, Walid Mohamed

November 2019

Idaho National Laboratory Idaho Falls, Idaho 83415

http://www.inl.gov

Prepared for the U.S. Department of Energy

National Nuclear Security Administration

Under DOE Idaho Operations Office

Contract DE-AC07-05ID14517 


\author{
Proceedings of the ASME 2019 \\ International Mechanical Engineering Congress and Exposition \\ IMECE2019 \\ November 11-14, 2019, Salt Lake City, UT, USA
}

IMECE2019-11547

\title{
EFFECTS OF PLATE CURVATURE ON THERMO-MECHANICAL PERFORMANCE OF U- 10MO MONOLITHIC FUEL PLATES
}

\author{
Hakan Ozaltun ${ }^{1}$ \\ Idaho National Laboratory \\ Idaho Falls, ID, USA
}

\author{
Hee Seok Roh \\ Argonne National Laboratory \\ Lemont, IL, USA
}

\author{
Walid Mohamed \\ Argonne National Laboratory \\ Lemont, IL, USA
}

\begin{abstract}
Monolithic fuel is a candidate fuel form being considered for the conversion of high-performance research reactors. This platetype fuel consists of a high-density, U-Mo fuel in a monolithic form that is sandwiched between zirconium diffusion barriers, and encapsulated in an aluminum cladding. To date, large number of plates have been irradiated with satisfactory performance. The program is now moving into the qualification phase, a predecessor to the timely conversion of the target reactors. Since each reactor employs distinct fuel plate geometries for various consideration, resulting nearly 50 distinct plate geometries with unique plate design features, a single "generic" plate geometry capturing all of the extremities is not achievable. This limitation consequently requires much more cautious performance evaluations, as thermal and mechanical response of a plate with certain geometry may not be representative for a plate with a different geometry. To evaluate the performance of the plates for various geometric parameters, parametric sensitives studies have been employed. One of the important geometric parameters may have potential effects on the performance is the plate curvature. In this study, curvedplates were parametrically simulated to investigate if this geometric parameter has any effects on overall performance, In particular, radius of curvatures of the plates were varied between the bounding values, and the plates were simulated for comparable irradiation histories. The resulted temperature, deformation, stress-strain results were comparatively evaluated. The results have indicated that preferential deformations occur. This consequently caused shifting of plate centerline on curved plates. The magnitude of centerline shifts increased with increasing plate curvatures.
\end{abstract}

Keywords: U-10Mo, Monolithic Fuel, Curvature

\footnotetext{
${ }^{1}$ Contact author: hakan.ozaltun@inl.gov, (208) 526-0274
}

\section{INTRODUCTION}

The main objective of Office of Material Management and Minimization (M3) is to achieve a permanent threat reduction by minimizing and eventually eliminating use of highly enriched uranium (HEU) around the world. This objective is being fulfilled by several subprograms: reactor conversion, material removal and disposition. Reactor conversion program aims to develop technologies to convert test reactors to operate with a proliferation resistant, low enriched uranium fuels. Although many test reactors can be converted with existing licensed LEU fuel, several high-power reactors require higher density fuels in a monolithic form. Two types of U-Mo fuel have been experimentally tested to meet reactor requirements, dispersion fuel and monolithic fuel. U-Mo dispersion fuel $\left(4.8 \mathrm{~g}-\mathrm{U} / \mathrm{cm}^{3}\right)$ has shown good performance for low fission densities. However, some high-power reactors require higher fuel densities $(>8.0 \mathrm{~g}$ $\mathrm{U} / \mathrm{cm} 3$ ) in a monolithic form in order to maintain high reactivity. Within this concept, US High Performance Research Reactors (HPRR) Fuel Qualification program has been developing monolithic U-Mo fuels to support reactor conversion efforts. The development of these fuels requires many design challenges to maintain sufficient reactor power levels, while continuing to meet safety and viability requirements. U-Mo alloy fuel is being considered due to its preferential response during irradiation. Studies have shown that molybdenum extends the cubic gamma phase, which provides increased stability under irradiation. Irradiation experiments demonstrated that U-10Mo based monolithic fuel system has a good swelling response and predictable in-service behavior $[1,2,3]$.

The use of a foil form of fuel creates number challenges and geometric parameters. Abundance of parameters raises concerns about the implications of plate geometry on the performance. To address these concerns, the new design should be benchmarked 
for such variables. However, it is impractical to test each of these design parameters in reactor. Instead, simulations provide a timely and cost-effective means to evaluate the performance of plates for variations in operational parameters, fuel plate design, material property, geometric irregularities, etc. that supplement the information obtained from irradiation testing.

To date, number of sensitivity studies have been performed to understand plate's sensitivity to various input variables, including (1) geometric parameters, (2) operational parameters, and (3) material property related parameters.

Currently, all USHPRRs have released designs for LEU monolithic fuel reactor core designs. While these designs may have changes, it is considered that they are sufficiently mature to be used in development efforts. The list below summarizes the fuel element designs currently considered as described in [4]:

a. ATR: Modified ELF concept, 19 unique plate types [5, 6].

b. HFIR: Graded fuel with burnable absorbers [7]

c. MITR: 19B25 design concept, three unique plate types [8]

d. MURR: CD35 design concept, 23 unique plate types [9]

e. NBSR: 34 plates per element, one unique type [10]

These unique plate designs necessitate nearly 50 distinct LEU plate geometries. Consequently, a single generic plate geometry representing all of the extreme points in this design matrix is not realistic, since both extremes of a given parameter could yield entirely different fabrication difficulties, as explained in details elsewhere [4].

Although MITR plate design has a flat profile, designs for ATR, MURR and NBSR have profiles with varying radius of curvatures as given in Table 1, Table 2 and Table 3.

Table 1 ATR Plate Designs

\begin{tabular}{cccc}
\hline $\begin{array}{c}\text { Plate } \\
{[\#]}\end{array}$ & $\begin{array}{c}\text { Plate Width } \\
{[\mathrm{mm}]}\end{array}$ & $\begin{array}{c}\text { Plate Thickness } \\
{[\mathrm{mm}]}\end{array}$ & $\begin{array}{c}\text { Plate Radius } \\
{[\mathrm{mm}]}\end{array}$ \\
\hline ATR, 1 & 53.823 & 2.007 & 76.581 \\
ATR, 13 & 83.236 & 1.245 & 116.281 \\
ATR, 19 & 100.584 & 2.515 & 135.636 \\
\hline
\end{tabular}

Table 2 MURR Plate Designs

\begin{tabular}{cccc}
\hline $\begin{array}{c}\text { Plate } \\
\text { [\#] }\end{array}$ & $\begin{array}{c}\text { Plate Width } \\
{[\mathrm{mm}]}\end{array}$ & $\begin{array}{c}\text { Plate Thickness } \\
{[\mathrm{mm}]}\end{array}$ & $\begin{array}{c}\text { Plate Radius } \\
{[\mathrm{mm}]}\end{array}$ \\
\hline MURR, 4 & 58.471 & 1.118 & 80.429 \\
MURR, 23 & 110.185 & 1.245 & 146.190 \\
\hline
\end{tabular}

Table 3 NBSR Plate Designs

\begin{tabular}{cccc}
\hline $\begin{array}{c}\text { Plate } \\
{[\#]}\end{array}$ & $\begin{array}{c}\text { Plate Width } \\
{[\mathrm{mm}]}\end{array}$ & $\begin{array}{c}\text { Plate Thickness } \\
{[\mathrm{mm}]}\end{array}$ & $\begin{array}{c}\text { Plate Radius } \\
{[\mathrm{mm}]}\end{array}$ \\
\hline ALL & 70.942 & 1.270 & 139.700 \\
\hline
\end{tabular}

Examining the values in the tables indicate radius of curvatures ranges from roughly $76 \mathrm{~mm}$ to $146 \mathrm{~mm}$. Although large number of plates were irradiated with satisfactory performance, it is not known if curvatures could have any effects of overall performance. This work evaluates the implications of plate curvatures on the thermal and mechanical performance to address these concerns.

\section{FINITE ELEMENT MODEL}

Models are fully coupled thermal-structural interactions with user defined parameters. For this work, a fully coupled 3D model of a monolithic plate with a capability to evolve mechanical and thermal properties of the constituent materials with irradiation time and burnup is utilized. The models used the plate geometry, irradiation history and coolant conditions as input. Output parameters included temperature, stress, strain, and deformation history during transient.

\subsection{Irradiation Model}

For this work, a mini-plate with a characteristic irradiation history was considered. The plate was assumed to be in face-on configuration, meaning the fuel faces to the reactor core center.

Irradiation parameters were sampled from MP-1 mini-plate experiments. For a conservative evaluation, plates were evaluated at high power with high burnup. In particular, average fission power density was taken as $32776 \mathrm{~W} / \mathrm{cm}^{3}$ (sampled from MP-1 high power experiment), average fission density at End of Life was taken as $7.7 \mathrm{E}+21$ [fissions $/ \mathrm{cm}^{3}$ ], giving nearly a full burnup, and finally, average fast neutron flux was taken as $2.220 \mathrm{E}+14\left[\mathrm{n} / \mathrm{cm}^{2}-\mathrm{sec}\right]$. Fission density local to average ratio (L2AR) in the fuel zone was taken as constant (i.e. no fission profile) to avoid any artificial effects that could be created by a non-linear fission distribution in the fuel zone.

\subsection{Behavioral Models}

Behavioral models for the fuel zone included elasticity, plasticity, thermal expansion, irradiation creep, volumetric swelling, modulus degradation, thermal conductivity degradation due to porosity. The thermal and mechanical models are based on temperature and burnup dependent data.

Cladding material in this study is aluminum. As-received aluminum is in T6 temper. However, HIP process effectively anneals the material, resulting in properties of similar to those for A16061-O, on which the cladding properties are based. Behavioral models for the cladding included elasticity, plasticity, thermal expansion, neutron hardening, thermal creep, irradiation growth. The models are based on temperature and fluence dependent data.

The diffusion barrier is ASM Grade 702 commercially pure Zirconium, on which the diffusion barrier properties are based 
for this work. Behavioral models of diffusion barrier included elasticity, plasticity, hardening, thermal expansion and thermal creep. Thermal and mechanical models are based on available temperature dependent data.

Additional details on behavioral models and the tabulated property data can be found in FQ's U-Mo report [11].

\subsection{Plate Curvature Model}

To understand possible effects of plate curvature on performance, plate curvature was varied and selected results were comparatively evaluated. In particular, while all geometric parameters (width, length and thickness) of the plate were kept constant, radius of curvature was varied between the bounding values, as illustrated schematically in Figure 1. Plate curvatures that were evaluated in this study and their specific reactor applications are summarized in Table 4.

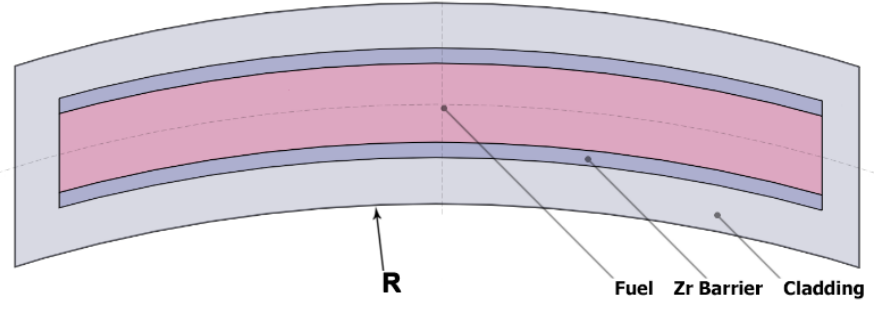

Figure 1 Schematics for plate curvature study

Table 4 Plate curvatures studied in this work

\begin{tabular}{cccc}
\hline $\begin{array}{c}\text { Plate } \\
\text { Curvature } \\
{[\mathrm{mm}]}\end{array}$ & $\begin{array}{c}\text { Remarks } \\
\text { Details }\end{array}$ & $\begin{array}{c}\text { Bottomline } \\
\text { Shift } \\
{[-]}\end{array}$ & $\begin{array}{c}\text { Centerline } \\
\text { shift } \\
{[\mathrm{mm}]}\end{array}$ \\
\hline 25.000 & - & 3.466 & 3.552 \\
50.000 & - & 1.640 & 1.660 \\
75.000 & - & 1.083 & 1.092 \\
76.581 & ATR 1 & 1.060 & 1.069 \\
80.429 & MURR 4 & 1.009 & 1.017 \\
100.000 & - & 0.810 & 0.815 \\
116.281 & ATR 13 & 0.696 & 0.699 \\
125.000 & - & 0.647 & 0.650 \\
135.636 & ATR 19 & 0.596 & 0.599 \\
139.700 & NBSR & 0.578 & 0.581 \\
146.190 & MURR 23 & 0.553 & 0.555 \\
150.000 & - & 0.539 & 0.541 \\
175.000 & - & 0.461 & 0.463 \\
200.000 & - & 0.404 & 0.405 \\
- & Flat & 0.000 & 0.000 \\
\hline
\end{tabular}

The models with various radius of curvatures were then simulated by using comparable irradiation parameters. The resulting distortions, stresses-strains and temperature fields were comparatively evaluated to make an assessment.

\subsection{Model discretization}

For the base model, the thickness of the fuel was represented by 6 layers. Cladding was discretized by 22 layers. For diffusion barrier, 3 layers were used. Nodal divisions in length and width directions are 210 and 52, respectively. This discretization scheme resulted in 240240 hexahedral elements.

Since only the radius of curvature was parametrically varied, and all other dimensions (length, width and thickness) were kept unchanged, same mesh density were used between the cases to avoid any errors that could be introduced due to different mesh setting. A sample discretization of the curved geometry is shown in Figure 2.

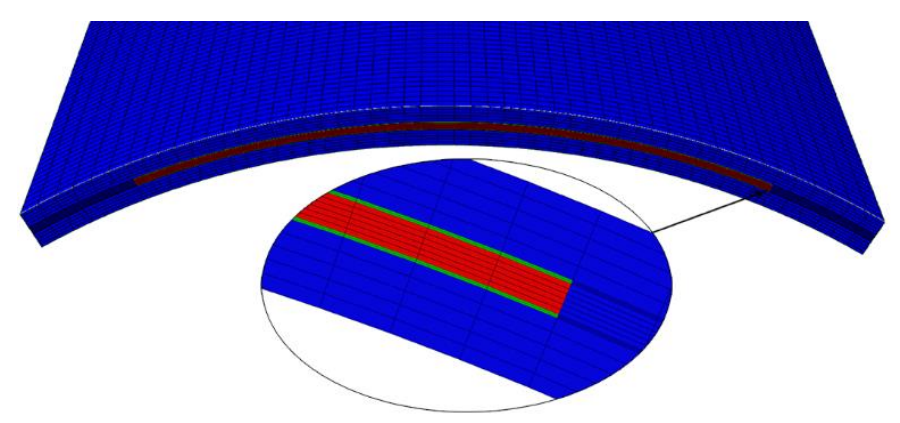

Figure 2 Model discretization

\section{RESULT AND DISCUSSIONS}

\subsection{Effects of curvature on stresses}

Table 5 shows a summary of peak stresses estimated for plates with curvatures. Although there is a slight variation on the peak stresses in the diffusion barrier, overall the effects were found to be insignificant. Closer examination of stresses in the fuel and cladding materials indicated that peak stresses are not affected by the radius of plate's curvature.

Table 5 Peak stresses at shutdown for various curvatures

\begin{tabular}{cccc}
\hline Curvature & \multicolumn{3}{c}{ Peak Equivalent Stress [MPa] } \\
\hline$[\mathrm{mm}]$ & Fuel & Cladding & Diff. Barrier \\
\hline 25.0 & 20.7 & 129.1 & 348.3 \\
50.0 & 21.1 & 129.1 & 337.1 \\
75.0 & 21.5 & 129.1 & 327.4 \\
100.0 & 21.7 & 129.1 & 324.3 \\
125.0 & 21.7 & 129.1 & 341.4 \\
150.0 & 21.8 & 129.1 & 326.1 \\
175.0 & 21.9 & 129.1 & 325.5 \\
200.0 & 21.9 & 129.1 & 329.4 \\
Flat & 22.4 & 129.1 & 324.3 \\
\hline
\end{tabular}


Figure 3 shows gives equivalent stresses in the fuel zone for various curvatures. Stresses are shown at the reactor shutdown. The results have indicated that the locations of peaks would stay the same (always closer to the fuel corners). Although there are slight differences, equivalent stresses are comparable between the cases. The magnitudes are relatively small, implying that effects of plate curvature on fuel stresses are significant. A similar trend was also observed for the stress profiles in the diffusion barrier and cladding materials. To better understand overall trends, stresses were also examined at the mid-plane of the plates.

Figure 4 shows stress profiles from the fuel centerline and at the cladding surface. Examination of profiles at centerline and plate surface revealed slight differences. However, the magnitudes of these differences were found to be insignificant. Comparative evaluation of these results has implied that plate curvature would not be a determining factor for the stresses in the fuel elements.
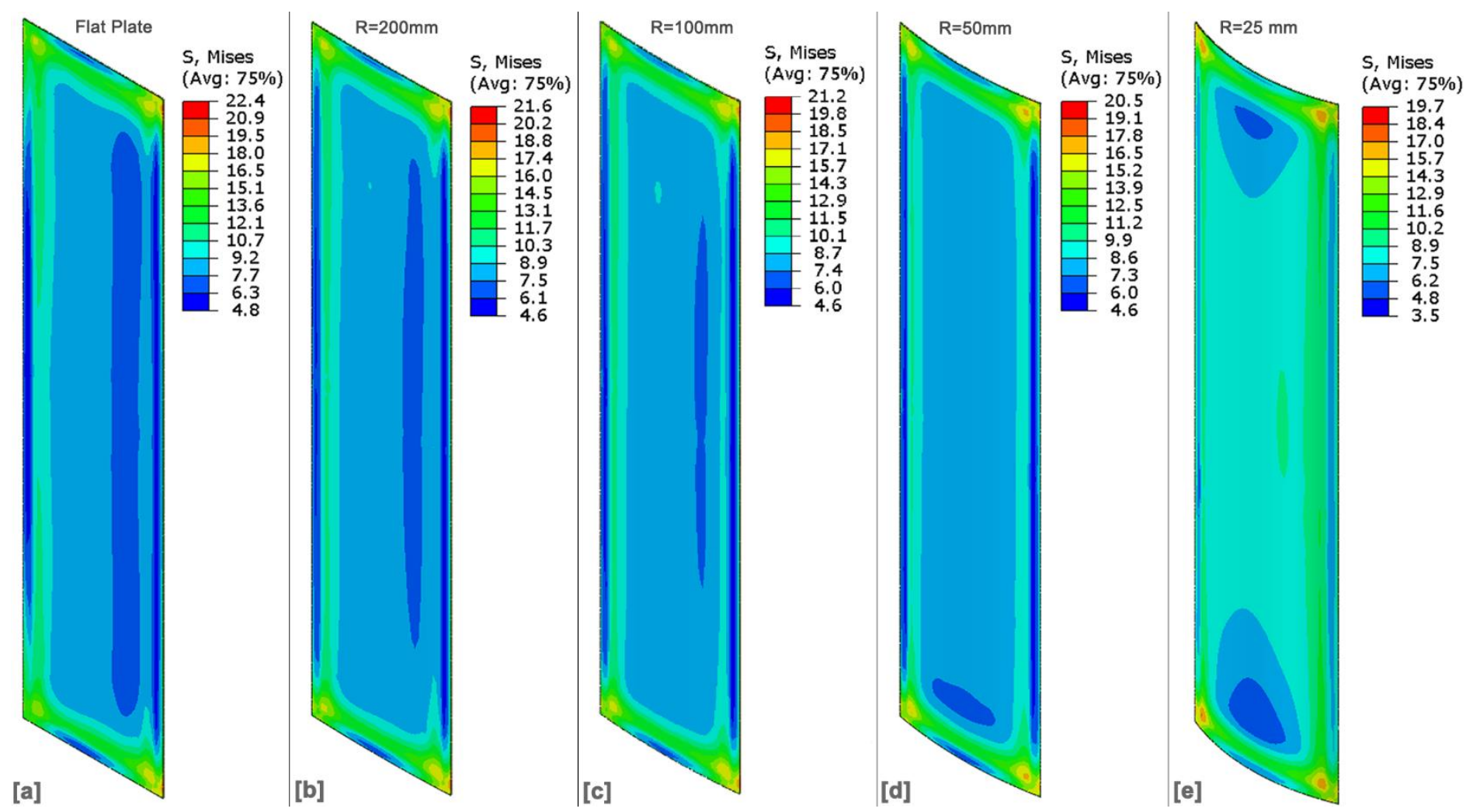

Figure 3 Fuel stresses for various plate curvatures (a) Flat plate (b) $R=200 \mathrm{~mm}$ (c) $\mathrm{R}=100 \mathrm{~mm}$ (d) $\mathrm{R}=50 \mathrm{~mm}$ (e) $\mathrm{R}=25 \mathrm{~mm}$
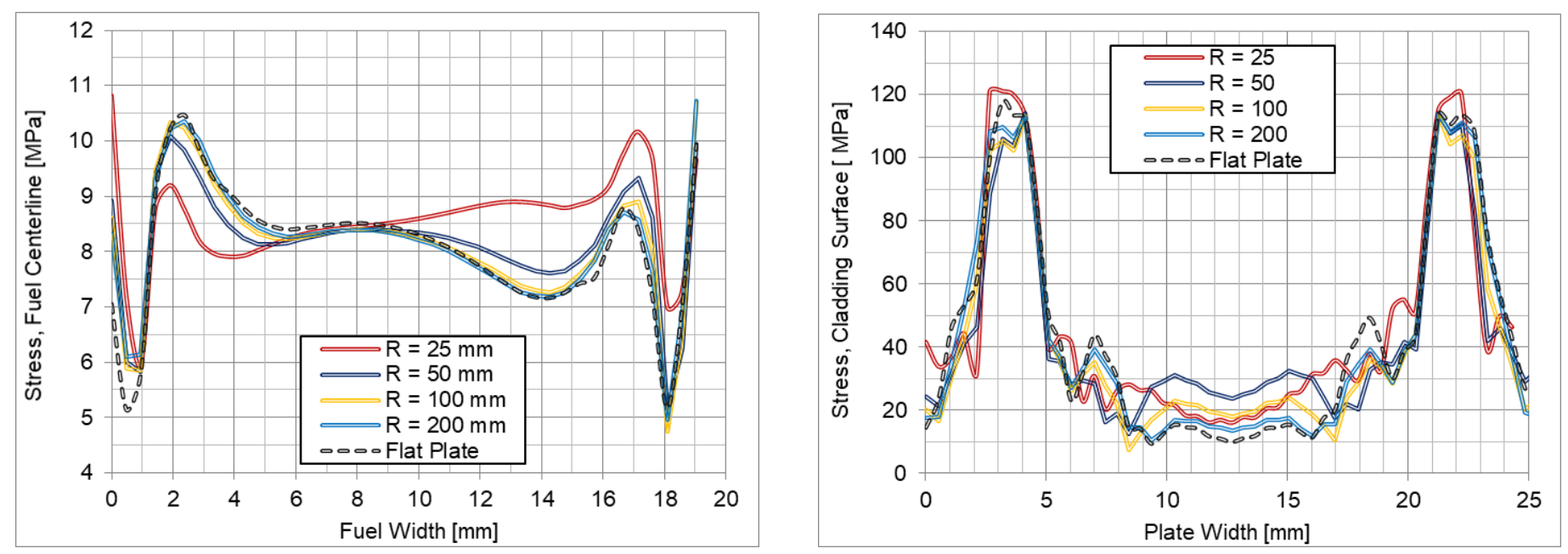

Figure 4 Stress profiles at the mid-plane for various curvatures (a) Fuel centerline (b) Cladding surface 


\subsection{Effects of curvature on temperatures}

Figure 5 and Figure 6 show temperature contours at the cladding surface and fuel centerline, respectively. Figure 7 compares these temperature profiles at the mid-plane for various plate curvatures. Finally, Table 6 shows peak temperatures at EOL estimated for cladding, diffusion barrier and fuel, as a function of plate curvature.

Comparative evaluation of these temperature results given for fuel centerline, cladding surface and global peaks indicated that temperatures are not affected by the curvature of the plates under normal irradiation conditions.

Table 6 Peak temperatures for various curvatures

\begin{tabular}{cccc}
\hline Curvature & \multicolumn{3}{c}{ Peak Temperatures $\left[{ }^{\circ} \mathrm{C}\right]$} \\
\hline$[\mathrm{mm}]$ & Fuel & Cladding & Plate Surface \\
\hline 25.0 & 164.3 & 117.1 & 106.2 \\
50.0 & 164.8 & 116.8 & 105.9 \\
75.0 & 165.1 & 116.7 & 105.9 \\
100.0 & 165.2 & 116.7 & 105.8 \\
125.0 & 165.2 & 116.6 & 105.8 \\
150.0 & 165.4 & 116.5 & 105.7 \\
175.0 & 165.7 & 116.6 & 105.7 \\
200.0 & 166.6 & 116.6 & 105.7 \\
Flat & 165.6 & 116.5 & 105.6 \\
\hline
\end{tabular}
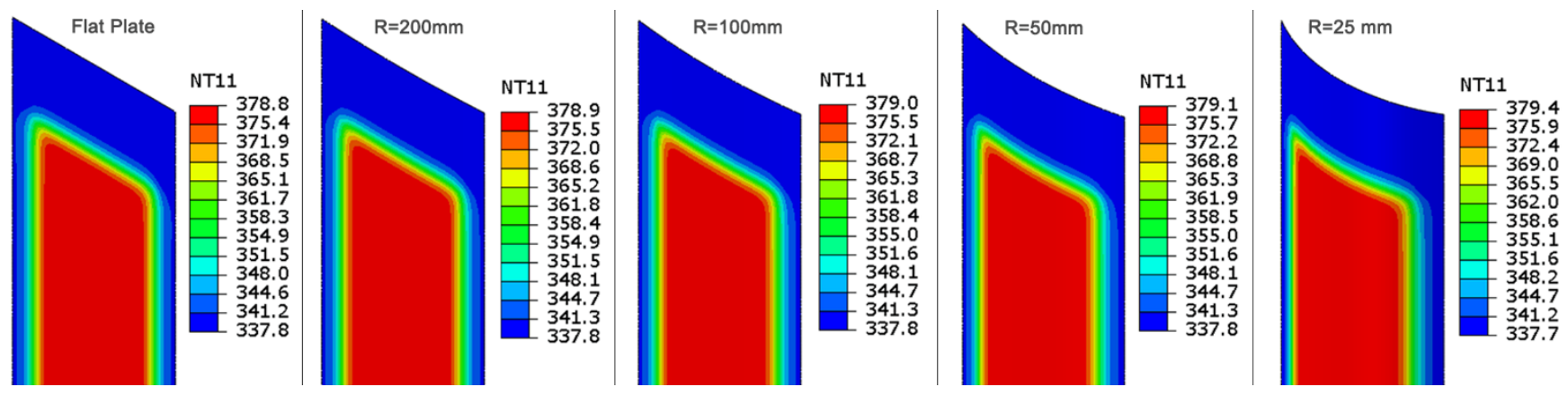

Figure 5 Temperatures [K] at the plate surface (a) Flat plate (b) $\mathrm{R}=200 \mathrm{~mm}$ (c) $\mathrm{R}=100 \mathrm{~mm}$ (d) $\mathrm{R}=50 \mathrm{~mm}$ (e) $\mathrm{R}=25 \mathrm{~mm}$
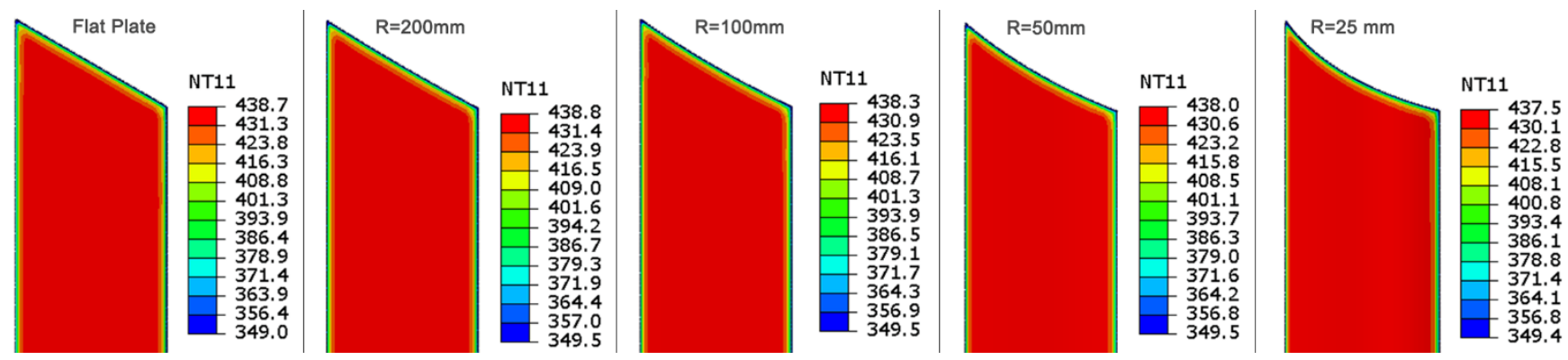

Figure 6 Temperatures $[K]$ at the fuel centerline (a) Flat plate (b) $R=200 \mathrm{~mm}$ (c) $\mathrm{R}=100 \mathrm{~mm}$ (d) $\mathrm{R}=50 \mathrm{~mm}$ (e) $\mathrm{R}=25 \mathrm{~mm}$
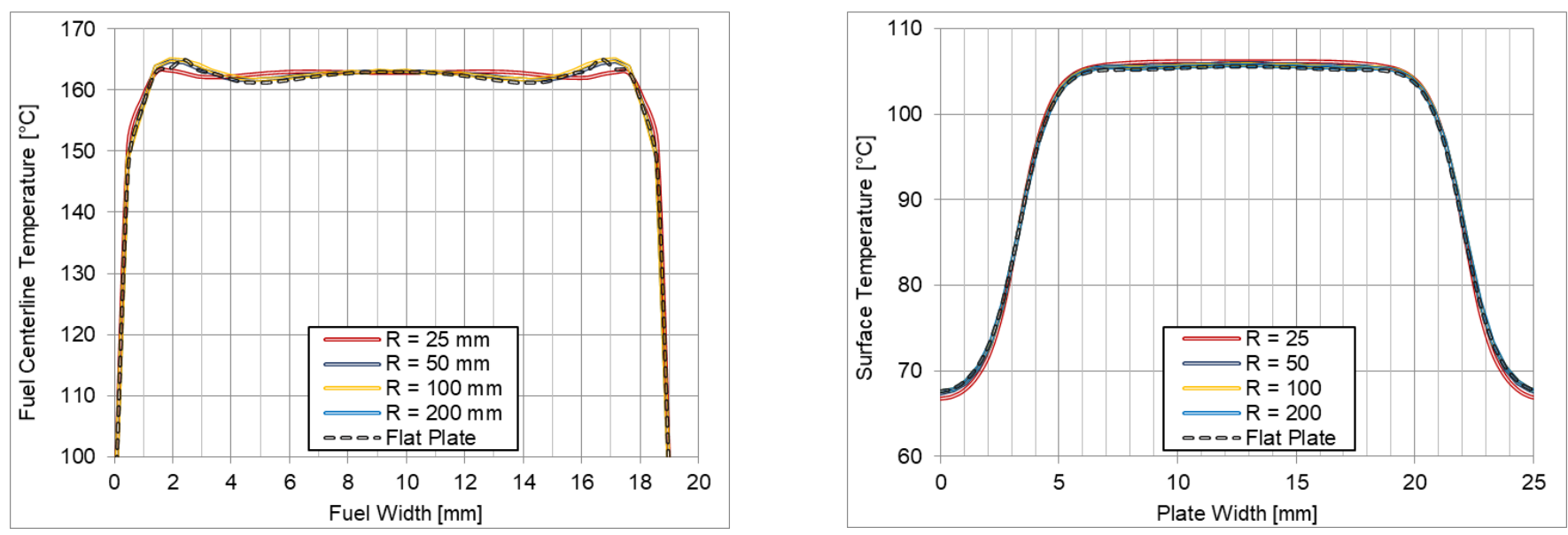

Figure 7 Temperature profiles at the mid-plane for various curvatures (a) Fuel centerline (b) Cladding surface 


\subsection{Effects of curvature on deformations}

Although effects of curvature on stresses and temperatures were found to be insignificant, effects of curvature on deformation characteristics of the plates were found to be considerable. significant. Figure 8 presents displacements of the plates for various curvatures. Contour plots indicate that the plate deformations are heavily affected by the degree of curvature.
While flat plates have displacement profiles mostly symmetric on opposite faces, these displacements magnitudes become highly preferential with an increasing plate curvature as observed in Figure 8. With an increasing curvature, the magnitude of these displacements would increase considerably.

Figure 9 shows deformation characteristics of plates with various curvatures. In Figure 9a, thickness increase of the fuel as a
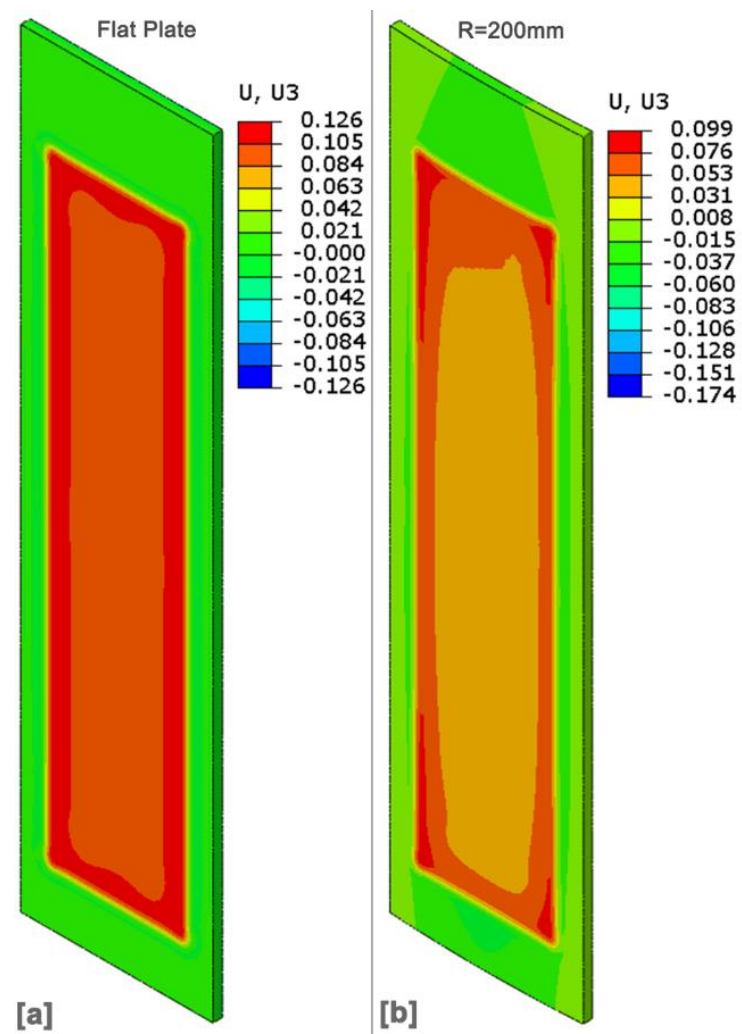

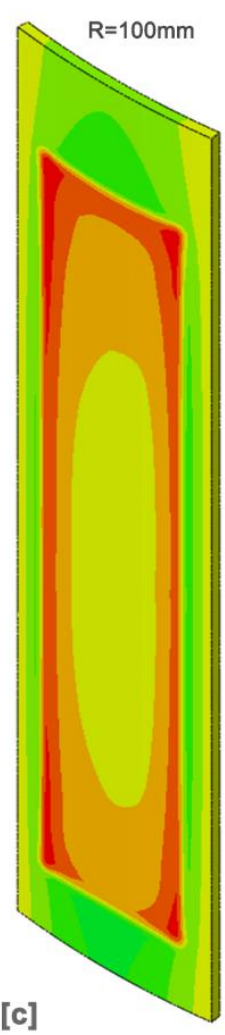

[c]
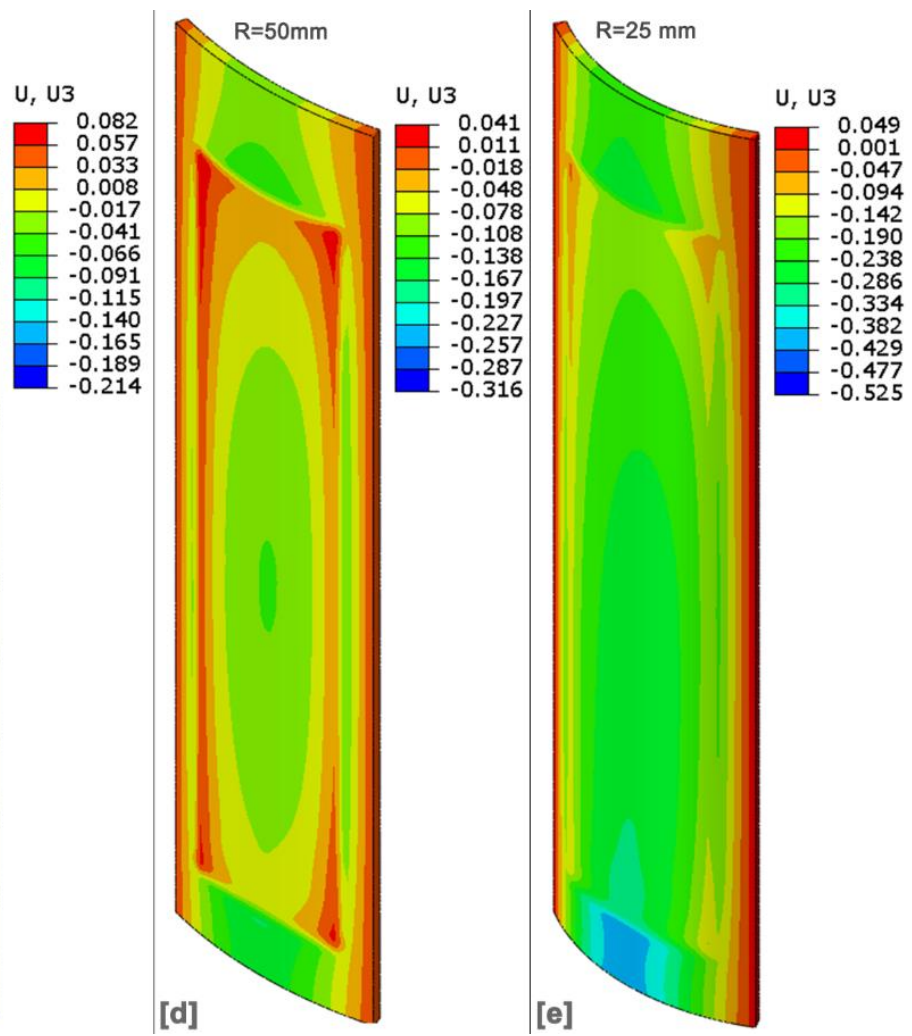

Figure 8 Displacements $(\Delta t)$ and deformation patterns (a) Flat plate (b) $R=200 \mathrm{~mm}$ (c) $\mathrm{R}=100 \mathrm{~mm}$ (d) $\mathrm{R}=50 \mathrm{~mm}$ (e) $\mathrm{R}=25 \mathrm{~mm}$
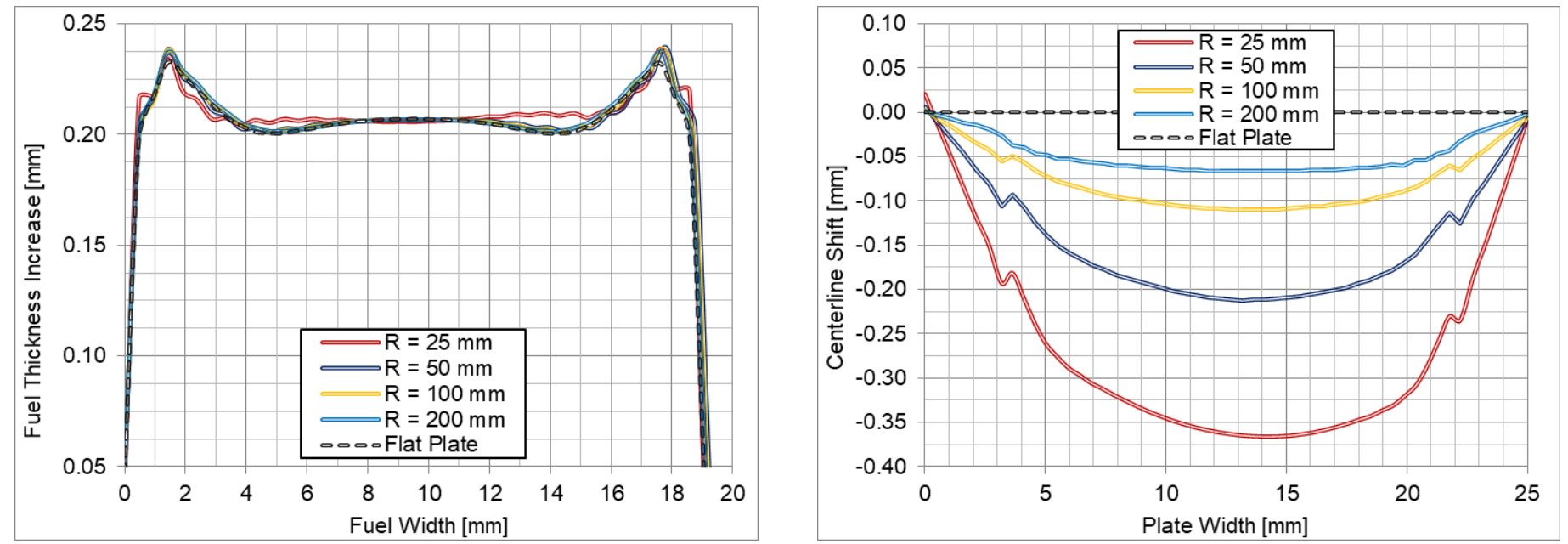

Figure 9 Deformations for various plate curvatures (a) Fuel thickness increase (b) Plate centerline shift 
function of fuel width is seen. The results indicate that the peaks and overall trend of the profiles are comparable to each other, regardless of the plate curvature. This implies that plate curvature is not an influential factor for the thickness increase of the fuel zone (i.e. swelling is not affected primarily by the degree of plate curvature)

To understand if curved plates are more prone to warping-type deformations, displacement profiles at the plate centerline were also examined. In Figure 9b, centerline shift of the plates with different curvatures are shown. The trends of the profiles showed that the plates with tighter curves (smaller radius of curvature) would have greater degree of centerline movement. It should be noted that the centerline of the plate shifts towards to the center of curvature (e.g. trying to make the geometry flatter)

Table 7 summarizes deformation magnitudes estimated for plates with various curvatures. The results indicate that peak thickness increase, total swelling and creep strains are relatively insensitive to the magnitude of the curvature. However, the results also indicate that plate centerline shifts would occur on curved plates. This shift would become more significant when the curvature is tighter.

Table 7 Peak deformations for various curvatures

\begin{tabular}{ccccc}
\hline $\begin{array}{c}\text { Radius of } \\
\text { curvature }\end{array}$ & $\begin{array}{c}\text { Centerline } \\
\text { Shift }\end{array}$ & $\begin{array}{c}\text { Thickness } \\
\text { Increase }\end{array}$ & $\begin{array}{c}\text { Swelling } \\
\text { Strain }\end{array}$ & $\begin{array}{c}\text { Creep } \\
\text { Strain }\end{array}$ \\
\hline$[\mathrm{mm}]$ & $\Delta, \mathrm{mm}$ & $\Delta \mathrm{t}, \mathrm{mm}$ & {$[\%]$} & {$[\%]$} \\
\hline 25.0 & -0.366 & 0.239 & 110.49 & 83.7 \\
50.0 & -0.212 & 0.239 & 110.80 & 84.7 \\
75.0 & -0.144 & 0.239 & 110.59 & 84.3 \\
100.0 & -0.110 & 0.238 & 110.46 & 83.8 \\
125.0 & -0.091 & 0.238 & 110.42 & 83.4 \\
150.0 & -0.080 & 0.048 & 110.32 & 83.5 \\
175.0 & -0.072 & 0.238 & 110.13 & 83.4 \\
200.0 & -0.067 & 0.237 & 109.90 & 83.3 \\
Flat & 0.000 & 0.233 & 107.74 & 82.8 \\
\hline
\end{tabular}

\section{CONCLUSIONS}

In this work, effects of plate curvatures on thermo-mechanical performance of plates were studied. To understand if there are any effects, curvature of the plates was varied. In particular, while all geometric parameters (width, length and thickness) of the plates were kept constant, and radius of curvature were varied between the bounding values. The resulting temperature, deformation, stress-strain results were comparatively evaluated with those from flat plate.

The results have indicated that peak stresses in the fuel, diffusion barrier and cladding materials are not affected by the radius of plate's curvature. Although stress profiles at centerline and plate surface showed slight differences, the magnitudes of these differences were found to be insignificant. Comparative evaluation of all stress results has implied that plate curvature would not be a determining factor for the stresses in the fuel elements.

Similar trends were observed for temperatures. Comparative evaluation of temperature results for fuel centerline, cladding surface and global peaks indicated that temperatures are not affected by the curvature of the plates under normal irradiation conditions.

Although effects of curvature on stresses and temperatures were insignificant, the effects on deformation characteristics were found to be considerable. For deformations, multiple output variables were examined, including total thickness increase, swelling, irradiation creep, centerline movement. Overall trend of the deformation profiles was comparable to each other, regardless of plate curvature. This implied that the plate curvature is not an influential factor for total thickness increase of the fuel. In addition, total swelling and creep strains were found to be relatively insensitive to the magnitude of the curvature.

On the other hand, the results clearly shown that centerline relocation would occur on curved plates, indicating presence of preferential deformations. This phenomenon consequently caused considerable shifts of plate centerline. The magnitude of centerline shift increased with increasing plate curvatures. The trends of the profiles showed that the plates with tighter curves (i.e. smaller radius of curvature) would have greater degree of movement. Centerline shift was found to be towards to center of curvature (e.g. reducing the curvature)

The results and conclusions presented here for ideal and symmetric cooling conditions. It should be noted that, if one of the cooling channels is restricted during operation, this would consequently would create non-symmetric cooling settings, generating thermal gradients on a curved geometry. Presence of thermal gradients could magnify centerline shifts, eventually causing structural instabilities.

\section{ACKNOWLEDGEMENTS}

This research made use of the resources of the HighPerformance Computing Center at Idaho National Laboratory, which is supported by the Office of Nuclear Energy of the U.S. Department of Energy and the Nuclear Science User Facilities under Contract No. DE-AC07-05ID14517.

\section{US DOE DISCLAIMER}

This work was supported by the U.S. Department of Energy, Office of Material Management and Minimization, National Nuclear Security Administration, under DOE-NE Idaho Operations Office Contract DE-AC07-05ID14517. This manuscript was authored by a contractor for the U.S. Government. The publisher, by accepting the article for publication, acknowledges that the U.S. Government retains a 
nonexclusive, paid-up, irrevocable, worldwide license to publish or reproduce the published form of this manuscript, or allow others to do so, for U.S. Government purposes.

\section{REFERENCES}

[1] J. L. Snelgrove, G. L. Hofman and M. K. Meyer, "Development of very high density low-enriched Uranium fuels," J. Nucl. Eng. Des., vol. 178, p. 119-12, 1997.

[2] M. K. Meyer, G. L. Hofman, S. L. Hayes and C. R. Clark, "Low temperature irradiation behavior of U-Mo alloy dispersion fuels," J. Nucl. Mater., vol. 304, pp. 221-236, 2002.

[3] J. M. Park, K. H. Kim, C. K. Kim, M. K. Meyer, G. L. Hofman and R. V. Strain, "The irradiation behavior of atomized U-Mo alloy fuels at high temperature," J. Met. Mater. Int., vol. 7, no. 2, p. 151-157, 2001.

[4] INL, "TEV-2009: Supporting Information for the Low Enriched Uranium Monolithic Fuel Design," Idaho National Laboratory, Idaho Falls, ID, 2016.

[5] K. Jamison, "TEV-1792: Conceptual Design Parameters for ATR LEU U-Mo Conversion Demonstration Experimental Irradiations," Idaho National Laboratory, Idaho Falls, ID, 2015.

[6] INL, "SPC-1694: Specification for Advanced Test Reactor Low Enriched Uranium (LEU) Fuel Elements," Idaho National Laboratory, Idaho Falls, ID, 2018.

[7] D. Chandler, D. Cook, G. Ilas, P. Jain and D. R. Renfro, "ORNL/LTR-2013/132: Conceptual Design Parameters for HFIR LEU U-Mo Fuel Conversion Experimental Irradiations," Oak Ridge National Laboratory, Oak Ridge, TN, 2013.

[8] A. W. E. Bergeron, G. Yesilyurt, F. Dunn, J. Stevens, L. Hu and T. Newton, "ANL/GTRI/TM-13/15: Low Enriched Uranium Core Design for the. Massachusetts Institute of Technology Reactor. (MITR) with Un-finned 12 mil-thick Clad UMo Monolithic Fuel," Argonne National Laboratory, Argonne, IL, 2013.

[9] J. Stillman, E. Feldman, J. Stevens, E. Wilson, L. Foyto, K. Kutikkad, J. C. McKibben and N. Peters, "ANL/RERTR/TM-13-1: Irradiation Experiment Conceptual Design Parameters for MURR LEU U-Mo Fuel Conversion," Argonne National Laboratory, Lemont, IL, 2013.

[10] N. Brown, J. Baek, A. Hanson, A. Cuadra, L.-Y. Cheng and D. Diamond, "BNL-99897-2013-IR: Irradiation Experiment Conceptual DesignParameters for NBSR Fuel Conversion," Brookhaven National Laboratory, Upton, NY, 2013.

[11] M. Meyer, B. H. Rabin, J. Cole, I. Glagolenko, W. Jones, J. F. Jue, D. Keiser, C. Miller, G. Moore, H. Ozaltun, F. Rice, A. Robinson, D. Wachs, W. Williams and N. Woolstenhulme, "Research and Development Report for
U-Mo Monolithic Fuel," Technical Report, INL/EXT-1740975. Idaho National Laboratory, Idaho Falls/ID., 2016. 